By this time next year, it is hoped that the new

legislation will establish the framework for the

registration of PCDs; and, although much

remains to be done, 2003 should see the first

PCDs joining a new GDC Register.

\title{
Reforming the GDC
}

The General Dental Council (GDC) will never be the same again. The long awaited, much needed reform of the Council is at last beyond the point of no return. This year the Council will change fundamentally, becoming smaller, more strategic and able to embrace the principles of modern regulation of healthcare. Along with the introduction of mandatory continuing professional development, the reconstitution of the Council forms the first phase of the Council's reform programme.

The second phase of the programme, to include the modernisation of the Council's fitness to practise arrangements and the establishment of the framework for the registration of professionals complementary to dentistry (PCDs) is well underway. Work has begun on the drafting of the necessary legislation following consultation and recent decisions of the Council. These developments will be a triumph after many years of debate, expectation and frustration over lack of definitive action.

PCD registration is exciting territory, extending the important public protection measures that professional regulation offers to the whole dental team. Developing ethical guidance, the approval of courses of training; establishing standards for entry on a register; and developing new fitness to practise procedures are all tasks in hand. Dentists will retain ultimate responsibility for the care of patients, but PCDs will be answerable to the GDC if they practise beyond the limits of their competence. By this time next year, it is hoped that the new legislation will establish the framework for the registration of PCDs; and, although much remains to be done, 2003 should see the first PCDs joining a new GDC Register.

The reform of the Council's conduct and health procedures is also significant. It will allow for a more comprehensive range of mechanisms and sanctions for protecting the public; a remedial framework for registrants whose performance has deteriorated; a more robust and integrated approach to the initial investigation and management of complaints and a separation of the 'hearings function' from the main business of the Council. To realise the goal of having effective, comprehensive regulation of the profession, there will be a growing need for more joined-up working'. This will involve members of the profession, professional organisations and institutions, the Department of Health and, very importantly, patients whose protection must remain at the heart of the programmes of reform. Improved communications and consultation will underpin such continuing collaboration and, at one and the same time, keep all interested parties informed of the progress made.

The Council will be consulting widely again this year. The timetable is tight, so timescales for consultation are inevitably short, but I urge all dental professionals to visit our website http://www.gdc-uk.org throughout the year, respond to GDC consultation documents and help shape the future regulation of the dental profession.

Frequently asked questions include: When will the Council's Performance Review and Non-NHS Patient Complaints schemes be operational? What is the timescale for the regulation of corporate dentistry? Will there be an opportunity to revisit the introduction of a register for dentists retired from clinical practice? And, not surprisingly: what retention fees will dentists, specialists and PCDs be required to pay in the future to support and strengthen the regulation of the profession?

Providing answers to these questions is one of the immediate challenges facing the existing Council. Depending on the timing of further amendments to the Dentists Act 1984, some of these matters may become pressing priorities for the reconstituted Council which should first meet in shadow form during the last quarter of 2002. With the GDC undergoing fundamental change, it is to be hoped there will be a new confidence and ownership in the professional regulation of dentistry - good news for patients, members of the dental team and the future of the profession.

\section{Nairn Wilson \\ President, GDC}

